\title{
REPERTORIO DE MEDICINA Y CIRUGÍA: TESTIGO FIEL DE LA PRÁCTICA MÉDICA COLOMBIANA
}

\author{
Marisol Goyeneche Reina*
}

En las colecciones de la biblioteca Arturo Aparicio Jaramillo reposan los primeros números de la revista Repertorio de Medicina y Cirugía, órgano oficial de la Sociedad de Cirugía en cuyas páginas se hizo un acercamiento al tipo de publicaciones y estructura que tenían las revistas de la época, que en su mayoría presentaban a los científicos y lectores artículos de prácticas medicas realizadas, estudios de mortalidad y enfermedades comunes para la población colombiana, traducciones de artículos hechas por los ilustres médicos de antaño que viajaban al viejo continente a conocer y traer los más recientes avances médicos europeos a Colombia. Entre estos ilustres hombres de la época que participaron en la revista está el Dr. Federico Lleras con el artículo "Las leches de Bogotá en la alimentación de los niños”. Encontramos al Dr. Juan NCorpas, quien publicó su trabajo para optar el título de médico titulado "La atmósfera de la altiplanicie de Bogotá y algunas de sus relaciones con la Fisiología y la Patología Humanas". En el volumen II número 1 se encuentra publicado el informe como presidente saliente de la Sociedad de Cirugía de Bogotá del Dr. José María Montoya, quien invita a la Junta Directiva y miembros de la Sociedad de Cirugía a seguir con la tarea de la construcción del Hospital diciéndoles: "Como lo veis por este informe todas las clases sociales nos secundan en nuestra empresa; no desmayemos, que el termino de nuestras Faenas esta ya próximo" y dado que no desfallecieron, hoy hace 84 años se encuentra en servicio el Hospital de San José.

En sus páginas versan diferentes temas médicos y sociales de la época, por ejemplo: el Dr. José del C. Cárdenas anexa al finalizar su artículo sobre "La lucha

* Directora de la Biblioteca Arturo Aparicio Jaramillo. Hospital de San José de Bogotá DC. Fundación Universitaria de Ciencias de la Salud. contra la Anemia Tropical", las certificaciones de los dueños de las fincas cafeteras en las cuales aplicó su tratamiento y recomendaciones. ¿ Medicina basada en la evidencia? "encontré la paciente quejándose, casi dando gritos del dolor" y suplicando que la aliviaran de cualquier manera, "aun cuando me tengan que rajar la barriga". Un feliz final dado a esta paciente adolorida dado por el ingenio del Dr. Uribe Botero, quien recordando un artículo sobre el uso de Higuerete en las Antillas, con un tallo de trigo, que es fistuloso y delgado, improvisó una sonda vesical y procedió a hacer el cateterismo a la señora que por fin pudo evacuar quedando tranquila y aliviada. "El hipnotismo es una de las más bellas conquistas de la ciencia. El hipnotismo es peligroso por el abuso que se puede hacer de él y la autoridad debe prohibir emplearlo a los que no sean médicos". A propósito de un bello tratado sobre el hipnotismo y espiritismo hecho desde la visión medica de la época por el Dr. Vela Briceño que vale la pena conocer. Estas son las palabras del Dr. Calvo, al revisar a su paciente después de una cirugía de rodilla hecha en la población de Honda, dando ejemplo de buena práctica, algo no tan fácil en el siglo XIX. "Pues además de que la pierna la hallé como lo esperaba, el estado general había mejorado de tal modo, que la niña por su robustez y buenos colores más parecía una bello modelo de tarjeta postal, que un convaleciente". A propósito de nuestro próximo bicentenario, recordamos que se encuentra publicado en el volumen 1 No. 10 de julio 23 de 1910 un número especial dedicado a todos aquellos médicos que participaron en la emancipación de la colonia española en el primer centenario del grito de independencia, al igual que el informe médico de la autopsia del cadáver del excelentísimo Señor Libertador General Simón Bolívar dada en San Pedro Alejandrino, diciembre 17 de 1830. 
Se encuentran en los diferentes números notas sobre los medicamentos en cuanto a la composición, gramaje y dosificación que hoy día cualquier laboratorio se rehusaría a publicar, notas sociales de los ires y devenires de los doctores y familias de la época. La invitación es a que se maravillen y transporten al ejercicio médico de la época en el lenguaje narrativo y poético que encuentran en todos los textos de Repertorio de Medicina y Cirugía, en donde cada uno de los autores pone en su escrito el conocimiento y sentimientos profesados por su profesión y su experiencia.

\section{Lecturas recomendadas}

Calvo, Jorge E. MD. Tratamiento de un tumor blanco de la rodilla por la resección de la misma. Bogotá, Colombia. Repertorio de Medicina y Cirugía. 1915; II(6): 300 .

Montoya, José Ma. MD. Informe del Presidente saliente de la Sociedad de Cirugía. Bogotá, Colombia. Repertorio de Medicina y Cirugía. 1910; II(1):4.

Ruan de la Carrera, Yolanda. Fuentes de Información Bibliográfica Médica a través de la historia. Bogotá, Colombia. Rivergráficas: 2008.

Uribe, Botero. Un caso de cateterismo en el campo. Bogotá, Colombia. Repertorio de Medicina y Cirugía. 1910; II(1): 89.

Vela Briceño, L. M. MD. Hipnotismo y Espiritismo. Bogotá, Colombia. Repertorio de Medicina y Cirugía. 1915; II(6):273. 